\title{
REFLEXÕES COMPARADAS SOBRE A ÉTICA UTILITARISTA NOS CONTOS "A CARTEIRA", DE MACHADO DE ASSIS, E "O CAPOTE", DE NIKOLAI GOGOL"
}

\author{
Júlia Lopes Penido Pena² \\ Marcus Vinícius de Freitas ${ }^{3}$
}

\begin{abstract}
Resumo: Sob a luz das obras A ética protestante e o "espírito" do capitalismo, de Max Weber (2007), e As ideias fora do lugar, de Roberto Schwarz (1992), este trabalho visa à análise comparativa dos contos "A carteira”, de Machado de Assis (2019), e “O capote”, de Nikolai Gogol (2001). Assim, a contraposição dos contextos das obras evidenciou grande semelhança entre as sociedades como Schwarz deixa claro -, o que reflete na proximidade das características morais das personagens dos contos. Tais características, sobretudo referentes à economia, deixam clara a discrepância da ética presente em países protestantes - descritos por Weber. Em “A carteira”, Machado nos apresenta Honório como protagonista, o qual preza pela imagem de homem honrado, e, principalmente, pela manutenção de seus créditos social e financeiro, ainda que desenvolva questionamentos morais ao longo do conto. Já em “O capote”, Gogol faz com que Akaki seja a representação do homem que preza pelo trabalho pelo viés tradicionalista - sem visar ao acúmulo de dinheiro ou ao lucro. Os contos analisados, por serem verossímeis, apresentam, respectivamente, características sociais do Brasil Império e da Rússia czarista e, portanto, suas personagens reproduzem padrões éticos vigentes na época - o
\end{abstract} que permite analisar e comparar as obras e os contextos em que estas estão inseridas. Por meio deste trabalho, a ética utilitarista - pregada por Benjamin Franklin e descrita por Weber - mostrou-se presente em ambas as sociedades, ainda que o tradicionalismo estivesse presente, o que evidenciou o fato de que tais elementos não são excludentes.

Palavras-Chave: Economia; Ética utilitarista; Literatura comparada; Machado de Assis; Nikolai Gogol.

\section{Introdução}

Ao iniciar uma análise cujo objetivo é comparar os contos “A carteira”, de Machado de Assis, e "O capote", de Nikolai Gogol, precisou-se contrapor as sociedades em

\footnotetext{
${ }^{1}$ Texto escrito por Júlia Lopes Penido Pena sob orientação do Prof. Dr. Marcus Vinícius de Freitas para o projeto O PAPEL DA MOEDA: literatura brasileira em torno do Encilhamento, em 2020.

${ }^{2}$ Graduanda em Letras pela Faculdade de Letras da Universidade Federal de Minas Gerais - FALE / UFMG. E-mail: julialopespenido@gmail.com.

${ }^{3}$ Ph.D. em Portuguese and Brazilian Studies pela Brown University e Pós-doutor pela Universidade de Campinas. Professor titular de Teoria da Literatura e Literatura Comparada pela FALE / UFMG. E-mail: marcus@letras.ufmg.br.
} 
que as obras estão inseridas. O conto de Machado, publicado em 1884, situa-se no contexto antecedente ao Encilhamento - em que a sociedade, monarquista, ainda era bastante hierarquizada. Já a obra de Gogol, publicada em 1842, situa-se na Rússia czarista - em que as desigualdades sociais, fruto de uma sociedade também hierarquizada, eram ainda mais evidentes. A partir da leitura de As ideias fora do lugar, de Roberto Schwarz (1992), percebe-se como o contexto econômico - que interfere diretamente nas concepções morais - de ambas as sociedades são similares, mesmo com uma diferença considerável em relação ao tempo e, sobretudo, ao espaço. Segundo o autor,

\begin{abstract}
O sistema de ambigüidades assim ligadas ao uso local do ideário burguês - uma das chaves do romance russo - pode ser comparado àquele que descrevemos para o Brasil. São evidentes as razões sociais da semelhança. Também na Rússia a modernização se perdia na imensidão do território e da inércia social, entrava em choque com a instituição servil e com seus restos, - choque experimentado como inferioridade e vergonha nacional por muitos, sem prejuízo de dar a outros um critério para medir o desvario do progressismo e do individualismo que o Ocidente impunha e impõe ao mundo. Na exacerbação deste confronto, em que o progresso é uma desgraça e o atraso uma vergonha, está uma das raízes profundas da literatura russa. Sem forçar em demasia uma comparação desigual, há em Machado - pelas razões que sumariamente procurei apontar - um veio semelhante, algo de Gogol, Dostoievski, Gontcharov, Tchecov, e de outros talvez, que não conheço (SCHWARZ, 1992, p. 14)
\end{abstract}

O primeiro conto a ser analisado é "A carteira”, de Machado de Assis. A história se passa na fase final do Brasil Império, que caminhava para a Primeira República e, consequentemente, para o Encilhamento. $\mathrm{O}$ texto se inicia desrespeitando a ordem cronológica dos acontecimentos: Machado apresenta a cena central de sua obra ainda no primeiro parágrafo - a de Honório encontrando e apanhando uma carteira na rua. Esse ato é o gatilho para a retomada do contexto: Honório possui dívidas geradas, sobretudo, pelos gastos excessivos com sua esposa, Amélia, a qual alegava estar aborrecida pela solidão, pois seu marido trabalhava demasiadamente. Em seguida, o autor nos apresenta Gustavo - amigo de Honório e frequentador de sua casa -, para quem Honório mente, dizendo estar numa situação financeira confortável. Em verdade, ele não revela sua situação financeira a ninguém, porém teme a pobreza e, com isso, encontra-se em um embate moral ao encontrar a carteira. Embora esteja numa situação embaraçosa, ele é um homem honrado - e, por isso, entra em uma série de reflexões sobre abrir ou não a carteira, e, posteriormente, ao perceber que havia mais dinheiro que o necessário para quitar sua dívida, faz-se questionamentos sobre pegar ou não a quantia. Por fim, Honório encontra alguns bilhetes, os quais não são abertos, e o cartão de visita de Gustavo, para quem ele decide, entristecido, devolver a carteira. Ao chegar em casa, Honório, sorridente, encontra Amélia e Gustavo e faz a devolução. Gustavo se mostra desconfiado e, quando Honório vai trocar de roupa, descobrimos que os papéis eram, na verdade, 
bilhetinhos de amor trocados entre Amélia e Gustavo. Este conto é, então, uma narrativa atemporal, e, além disso, observa-se que o autor cria personagens verossímeis, que podem ser facilmente adaptados à realidade, embora não sejam reais.

Já o segundo texto de base para comparação é “O Capote”, escrito por Gogol. O conto se passa na Rússia czarista e tem como foco narrativo um funcionário público órfão, pobre e pertencente a um cargo baixo, que sofre anualmente com o frio e, no trabalho, é alvo de piadas e humilhações de seus colegas. Assim, as dificuldades permeiam a vida de Akaki Akakievitch em diversos eixos de sua vida, porém ele jamais se dissocia de seu trabalho e, sobretudo, de seu cargo naquela repartição pública. Em dado momento, ele se depara com a necessidade de comprar um capote novo, pois não havia conserto para o antigo e o frio já o machucava. A partir desse ponto, sua vida ganha sentido, na medida em que suas ações são pensadas tendo como objetivo a conquista do novo capote. Ao conseguir comprá-lo, Akaki tem a sensação de elevação social, mesmo permanecendo na pobreza e no mesmo cargo no trabalho. O capote é, então, o símbolo de manutenção e, posteriormente - com a nova aquisição -, da sensação de ascensão social de Akaki; além de ser um importante objeto de percepção de seus colegas sobre ele, pois seu novo capote o dá notoriedade naquele ambiente, o faz ser respeitado e, até mesmo, torna-se motivo de uma festa. No entanto, essa ilusão se desfaz rapidamente: logo alguns homens roubam o capote de Akaki e, embora ele busque ajuda, um membro mais alto da organização judicial o humilha. Em seguida, sua frustração e o frio o adoecem e ele morre. A partir desse momento, a narrativa transforma-se numa volta fantástica e se desprende da verossimilhança, pois Akaki se torna um fantasma e começa a assombrar a cidade, roubando os capotes dos vivos, até que ele sossega após conseguir o capote do personagem importante que o humilhou quando foi procurado para ajudá-lo.

Esta análise se aterá, então, a questões comportamentais e éticas das personagens principais dos contos referenciados.

\section{A Economia aplicada à Literatura}

A partir da leitura de A ética protestante e o "espírito" do capitalismo, de Max Weber, esta análise se propõe a contrastar elementos do texto a alguns pontos que Weber elenca como sintomas do embrião do capitalismo moderno - o qual se manifesta na expressão ética de cada indivíduo e é, portanto, um fenômeno de massa. Além disso, este artigo busca evidenciar de que forma a concepção de Benjamin Franklin - time is money - e a ética utilitarista são aplicadas ao comportamento das personagens analisadas.

Em sua obra, Weber propõe que a cultura do capitalismo moderno antecede seu surgimento, de modo antagônico à concepção marxista. Para isso, ele descreve o surgimento desse sistema como consequência do desenvolvimento do calvinismo e contrapõe a ética de sociedades tradicionalistas ao que ele chama de "ética 
protestante" - raiz do capitalismo moderno. Ao discorrer sobre a ética capitalista, o autor retoma um texto de Benjamin Franklin, Time is Money, que retrata o "utilitarismo ético" - adverso ao ócio - e incentiva o acúmulo de bens e a poupança.

Assim, a ética utilitarista impõe que o sujeito deve, entre outras coisas, pagar suas contas em dia, uma vez que essa atitude determina a manutenção do seu crédito - que se relaciona à confiabilidade e, também, ao crédito financeiro, como fica claro no seguinte trecho de Benjamin Franklin:

\begin{abstract}
A par de presteza e frugalidade, nada contribui mais para um jovem subir na vida do que pontualidade e retidão em todos os seus negócios. Por isso, jamais retenhas dinheiro emprestado uma hora a mais do que prometeste, para que tal dissabor não te feche para sempre a bolsa de teu amigo.
\end{abstract}

As mais insignificantes ações que afetam o crédito de um homem devem ser por ele ponderadas. As pancadas de teu martelo que teu credor escuta às cinco da manhã ou às oito da noite o deixam seis meses sossegado; mas se te vê à mesa de bilhar ou escuta tua voz numa taberna quando devias estar a trabalhar, no dia seguinte vai reclamar-te o reembolso e exigir seu dinheiro antes que o tenhas à disposição, duma vez só.'

Isso mostra, além do mais, que não te esqueces das tuas dívidas, fazendo com que pareças um homem tão cuidadoso quanto honesto, e isso aumenta teu crédito (WEBER, 2007, p. 43 - 44).

Ademais, o espírito do capitalismo moderno faz com que o sujeito, além de se sentir na obrigação de manter a ética do trabalho para a manutenção de sua aparência, pense no dinheiro como seu próprio fim - e não como meio de conquista de bens -, aplicando a crematística, de modo que o jogo na bolsa de valores, ou qualquer meio de obtenção de lucro, seja valorizado. Com essa perspectiva de comportamento humano, é possível perceber como a rotina dos indivíduos se tornou auto exploradora. Assim, quando ocorre o rompimento com o tradicionalismo católico, o comportamento ético passa a ser regulado pelo próprio sujeito, e não mais por uma instituição como a Igreja - o que faz com que o lucro seja alcançado de forma mais efetiva.

Essas concepções serão, então, aplicadas ao comportamento dos protagonistas dos contos A carteira, de Machado, e O capote, de Gogol - os quais retratam as sociedades de sua época e sua moral vigente. Assim, será possível contrastar a ética utilitarista e a expressão comportamental de sujeitos comuns dos contextos das obras.

\title{
2 A ética de Honório e de Akaki em face à Economia
}

Evidenciada por Schwarz, a similaridade do contexto histórico dos contos de Machado de Assis e de Nikolai Gogol - o Brasil monarquista e a Rússia czarista 
-, possibilita estabelecer uma relação de correspondência entre a predominância da ética tradicionalista do trabalho em ambos os cenários. Essa relação fica nítida ao se comparar o comportamento e, portanto, a ética de Honório, em "A carteira", e de Akaki, em" O capote". Assim, evidencia-se o quanto os contextos econômico e social refletem na conduta seguida pelas comunidades e na ética individual em uma sociedade.

\subsection{A ética utilitarista de Honório em A Carteira}

Neste conto, Machado de Assis utiliza o recurso in media res e logo nos apresenta Honório, de modo que passamos a ter a visão do protagonista em relação aos fatos e às questões morais que sucedem. Assim, ao longo do texto, Machado joga tais questionamentos para o leitor. Entretanto, para além do olhar enviesado pela moralidade e pela traição presente no conto, é possível analisar a obra machadiana sob a ótica da economia, uma vez que a ética utilitarista está presente, assim como são aplicáveis alguns pensamentos weberianos nessa discussão.

Antes das considerações pontuais sobre o conto, é importante atentar para o sentido de ética utilitarista, a qual foi simplificada por Weber no seguinte trecho:

No fundo, todas as advertências morais de Franklin são de cunho utilitário: a honestidade é útil porque traz crédito, e o mesmo se diga da pontualidade, da presteza, da frugalidade também, e é por isso que são virtudes: donde se conclui, por exemplo, entre outras coisas, que se a aparência de honestidade faz o mesmo serviço, é o quanto basta, e um excesso desnecessário de virtude haveria de parecer, aos olhos de Franklin, ura desperdício improdutivo condenável (WEBER, 2007, p. 45-46).

Em primeiro lugar, em relação à obra machadiana, o autor não escolhe o nome do protagonista, Honório, ao acaso. Seu nome "[t]em origem no latim Honoriu, nome formado pela junção da palavra honor, que quer dizer 'honra, reputação' com o sufixo io, e significa 'homem honrado, homem de reputação"” 4 e é dessa forma que ele se apresenta no conto. Embora questionamentos de ordem moral, como os apresentados a seguir, perpassem a construção do personagem, sua honra é inabalável, pois o próprio sujeito a impõe e a cobra - conforme Max Weber detalha como rompimento com o tradicionalismo religioso em $A$ ética protestante e $o$ "espírito" do capitalismo. ${ }^{5}$

Ademais, ressalta-se que os nomes de outras personagens também não são escolhidos aleatoriamente. Amélia - esposa de Honório -, cujo nome quer dizer "trabalho" enuncia, então há o rompimento de seu significado em razão da sua desonestidade,

\footnotetext{
${ }^{4}$ https://www.dicionariodenomesproprios.com.br/honorio/

${ }^{5}$ WEBER, 2007, p. 30.

${ }^{6} \mathrm{https}$ ://www.dicionariodenomesproprios.com.br/amelia/
} 
de sua traição a Honório - o que nos indica a proximidade entre o comportamento moral e a confiança social (crédito), em consonância com as postulações de Weber. O nome da terceira personagem, Gustavo, também é categórico, uma vez que significa "protegido por Deus" " e, no conto, é quem tem sua traição quase descoberta pelo amigo, na medida em que este esteve diante das provas da relação entre Gustavo e Amélia e decidiu não as ver, pois não percebia motivos para desconfiar do amigo em razão de sua honra. Assim, os nomes dos envolvidos no triângulo amoroso já enunciam as questões que envolvem a moral no que diz respeito à traição. Entretanto, este trabalho busca fazer observações sob o viés da economia na ética de Honório.

No trecho a seguir, presente no primeiro parágrafo do conto, o narrador apresenta Honório ao leitor, juntamente da sua ética, embora ele a revele sutilmente. Após encontrar a carteira e pegá-la instantaneamente, Honório - por meio da escolha da sucessão de observações que o narrador faz em razão de seu foco narrativo ser centrado no protagonista - aparenta não perceber a presença de um observador naquela cena, e essa desatenção parece ser fundamental para explicar seu ato de pegar uma carteira cujo dono ele desconhece até então.

Ninguém o viu, salvo um homem que estava à porta de uma loja, e que, sem o conhecer, lhe disse rindo:

- Olhe, se não dá por ela; perdia-a de uma vez

- É verdade, concordou Honório envergonhado (ASSIS, 2019, p. 7).

Ao se revelar envergonhado, Honório demonstra iniciar suas reflexões morais, uma vez que passa a existir o questionamento de sua conduta por haver um observador. Assim, ele começa a expressar sua ética utilitarista - o que fica nítido ao compararmos essa cena ao seguinte trecho da obra weberiana: "As mais insignificantes ações que afetam o crédito de um homem devem ser por ele ponderadas." ${ }^{8}$ Nesse sentido, é possível pensar que Honório se questiona se aquele ato poderia ser socialmente condenável no que diz respeito a sua honra, e tal questionamento acontece por alguém tê-lo visto apanhando a carteira. Assim, Machado inicia o jogo com o leitor - o qual passa a ter domínio do julgamento das ações de Honório como se fosse ele mesmo, de forma que o leitor se faz os mesmos questionamentos que o personagem.

Em seguida, Honório mostra sua face utilitarista de forma mais evidente ao mentir sobre sua situação financeira com o objetivo de manter sua confiabilidade, ou seu crédito, nas palavras de Benjamin Franklin. Quando mente que sua situação

\footnotetext{
${ }^{7}$ https://www.dicionariodenomesproprios.com.br/gustavo/

${ }^{8}$ WEBER, 2007, p. 43.
} 
financeira é favorável, Honório percebe que rompe com a filosofia da avareza $a^{9}$, pois tem consciência de que seus gastos com os caprichos da esposa são desnecessários e que assumir que isso prejudica suas finanças é desfavorável para seu crédito. $\mathrm{Na}$ verdade, o fato de não se falar nem com Amélia sobre as situações financeiras - favoráveis ou desfavoráveis - e agir como se vivesse sempre em prosperidade revela uma preocupação com a manutenção de sua aparência e, portanto, de sua credibilidade. Contudo, na cena em que está aos prantos com a filha, Honório mostra-se preocupado com o futuro e que, no campo da individualidade, ele não nega sua situação. Essa cena, inclusive, serve como reforço da equivalência do significado de seu nome com sua conduta - revela que Honório tem uma filha e que é zeloso para com ela - e, portanto, tem uma família completa e é digno de honra, uma vez que a sociedade $a$ atribui à prosperidade da família nesse contexto.

Ao amenizar a situação de Honório, o narrador diz que ele "[e]stava com trinta e quatro anos; era o princípio da carreira: todos os princípios são difíceis. E toca a trabalhar, a esperar, a gastar, pedir fiado ou: emprestado, para pagar mal, e a más horas" ${ }^{10}$. Assim, a ética do trabalho se fortalece, pois, sob esse viés, a conquista de bens é fruto do trabalho honesto. Além disso, Honório mostra-se preocupado com o pagamento da dívida em dia, sobretudo após o credor agir de forma ofensiva com ele - reforçando as postulações de Franklin de que "nada contribui mais para um jovem subir na vida do que pontualidade e retidão em todos os seus negócios." 11 e obedecendo à seguinte advertência: "jamais retenhas dinheiro emprestado uma hora a mais do que prometeste, para que tal dissabor não te feche para sempre a bolsa de teu amigo." ${ }^{12}$

O ápice dos questionamentos morais de Honório chega quando ele se encontra no embate entre abrir ou não a carteira, pois essa ação poderia afetar diretamente seus atos futuros e sua concepção sobre a própria honra, como podemos ver na seguinte passagem:

\begin{abstract}
Ao mesmo tempo, e esta era a causa principal das reflexões, a consciência perguntava-lhe se podia utilizar-se do dinheiro que achasse. Não lhe perguntava com o ar de quem não sabe, mas antes com uma expressão irônica e de censura. Podia lançar mão do dinheiro, e ir pagar com ele a dívida? ${ }^{13}$
\end{abstract}

Nesse momento, Machado dá ao leitor a oportunidade de refletir sobre a ética do protagonista e sobre as ações futuras, levando-o a se colocar no lugar de Honório e fazendo com que os questionamentos sejam feitos juntamente ao personagem. Além disso, a "expressão irônica de censura” revela a substituição

\footnotetext{
${ }^{9}$ WEBER, 2007, p. 45

${ }^{10}$ ASSIS, 2019, p. 8.

${ }^{11}$ WEBER, 2007, p. 44.

${ }^{12}$ WEBER, 2007, p. 43.

${ }^{13}$ ASSIS, 2019, p. 8.
} 
da dominação eclesiástica pela dominação da própria consciência sob o comportamento do indivíduo, que é mais rigoroso - o que indica um distanciamento do tradicionalismo religioso, conforme Weber. ${ }^{14}$ Em consonância com o próprio nome, a consciência de Honório o leva a decidir entregar a carteira à polícia, talvez num exercício de manter sua integridade para si e, portanto, para os outros também. Contudo, imediatamente as pressões da situação o levam a refletir sobre suas necessidades do momento, de forma a tentar se convencer de que, naquela situação, outras pessoas não titubeariam em ficar com a carteira para si - o que revela o utilitarismo de sua ética, já que o contexto social é crucial para sua tomada de decisão, que foi abrir a carteira.

No momento em que a carteira é aberta, a quantidade de dinheiro leva Honório a conflitar sua ética do trabalho com a ética da loteria, da sorte, pois o dinheiro presente ali quitaria suas dívidas, como o narrador explicita na tentativa de Honório driblar sua própria conduta, no seguinte trecho, que expressa sua consciência: "Ninguém viu, ninguém soube; podia ser um lance da fortuna, a sua boa sorte, um anjo... Honório teve pena de não crer nos anjos". ${ }^{15}$ Nesse momento, fica claro, também, seu rompimento com o tradicionalismo católico - o que não significa sua aproximação com o protestantismo, mas a prioridade da sua honra em relação a imposições religiosas sobre a virtude. De forma mais nítida, sintetiza-se esse assujeitamento à aparência honrada - para os outros e para si - no pensamento de que "Se houver um nome, uma indicação qualquer, não posso utilizar-me do dinheiro". ${ }^{16}$ Aqui, Honório se mostra preocupado em cometer um roubo - um ato ilícito.

Ainda durante seus questionamentos morais, Honório descobre que a carteira é de seu amigo, Gustavo - e tal descoberta encerra qualquer dúvida em relação ao que fazer. Nesse momento, ele encontra alguns bilhetes e decide não os abrir, uma vez que projeta a própria honra no amigo. Embora decida devolver a carteira ao dono, Honório se entristece, revelando uma moral conflitante, porém sua conduta permanece íntegra. Em seguida, ao chegar em casa, avistou Gustavo e Amélia: "Entrou rindo, e perguntou ao amigo se lhe faltava alguma cousa" ${ }^{17}$ - retomando sua discrição em relação às questões financeiras.

Em seguida, há uma confusão entre a percepção de Honório e de Gustavo em relação à cena: enquanto este teme ter sido descoberto através dos bilhetes $\mathrm{e}$ demonstra estar desconfiado, aquele se chateia por ter interpretado essa desconfiança como possibilidade de roubo do dinheiro que havia na carteira entregue. Assim, como prova de sua honestidade, Honório dá explicações precisas sobre onde encontrou o objeto. A narrativa tem como perspectiva a honestidade, a honra e a confiança - a qual Honório deposita no amigo (por corresponder a tal confiança), por isso o narrador revela a traição apenas no último parágrafo do conto, como

\footnotetext{
${ }^{14}$ WEBER, 2007, p. 30 - 31.

${ }^{15}$ ASSIS, 2019, p. 9.

${ }^{16}$ idem.

17 ibidem.
} 
uma observação para o leitor. Assim, Machado joga o problema da moralidade para o leitor: ele se identifica com a honestidade de Honório?

Com essa análise, podemos afirmar, portanto, que o utilitarismo está presente na conduta de Honório - o que não significa que há o rompimento com o tradicionalismo econômico e nem religioso, uma vez que seu objetivo de vida não é o lucro.

\title{
2.2 0 tradicionalismo econômico em "O Capote"
}

Assim como Machado, Gogol não faz uma escolha aleatória do nome de seu personagem principal:

\begin{abstract}
Akaki em grego significa "não fazer o mal nezloblivy”. Um homem que usa um nome raro, geralmente alguns indeciso e irregular - isso se aplica a ambos os seus pensamentos e ações. [...] É sobre estes dizer que eles "não são mal a uma mosca". [...] Ele não era particularmente bem sucedido, mas se esforça e tem uma reputação de trabalhadora. ${ }^{18}$
\end{abstract}

Nesse sentido, o nome do protagonista já enuncia sua expressão subjetiva e sua ética, em relação à dificuldade comunicativa reiterada no conto, ao emprego mal remunerado e a sua conduta de trabalhador. Contudo, sua morte sobrepuja esse significado: ele busca por vingança ao assombrar a cidade. Sob a perspectiva weberiana, em vida Akaki corrobora a manutenção do tradicionalismo e segue a ética do trabalho, uma vez que, embora viva pelo trabalho, ele não segue a lógica de Benjamin Franklin, de que "tempo é dinheiro". Assim, o personagem não visa ao lucro, e o fato de ele não trabalhar a mais e, anteriormente, ter recusado subir de cargo em razão do aumento de esforço exigido demonstra sua falta de ambição. Assim, ele recorre à economia de meios de subsistência, como comida, para conseguir comprar o novo capote e, assim, ascender socialmente, mesmo que de forma ilusória.

Ao contrapor o pensamento weberiano à conduta de Akaki, o tradicionalismo de Akaki se explicita.

Eis um exemplo justamente daquela atitude que deve ser chamada de "tradicionalismo": o ser humano não quer "por natureza" ganhar dinheiro e sempre mais dinheiro, mas simplesmente viver, viver do modo como está habituado a viver e ganhar o necessário para tanto. ${ }^{19}$

No início do conto, o narrador já ilustra e sintetiza de que forma o tradicionalismo é combinado à ética do trabalho e, de certa forma, ao utilitarismo na conduta do protagonista - o que acontece, por exemplo, nos seguintes trechos:

\footnotetext{
${ }^{18}$ https://pt.dreambook.in.ua/name/man/akakiy/

${ }^{19}$ WEBER, 2007, p. 53.
} 
Ninguém lembrava em que época Akaki Akakiévitch havia ingressado no ministério e quem o havia recomendado. Por mais que mudassem os diretores, os chefes de divisão, os chefes de serviços e todos os demais, eles o encontravam sempre no mesmo lugar, na mesma atitude, ocupando a mesma tarefa expedicionária, se bem que na sequência tenham sido levados a concluir que ele viera ao mundo usando uniforme e com a cabeça raspada. $[. . .]^{20}$

Dificilmente encontraríamos um funcionário tão profundamente dedicado a seu trabalho quanto Akaki Akakiévitch. A ele se entregava com todo zelo; não, isso seria pouco: a ele se entregava com todo amor. ${ }^{21}$

O fato de ele ser associado sempre ao trabalho vai de encontro à manutenção de seu crédito. Por ele ser pobre, seu crédito se associa mais à questão social, que diz respeito à sua confiabilidade e à sua moralidade, do que à questão financeira. Assim, a ética do trabalho está muito presente na vida de Akaki, inclusive de forma subjetiva, haja vista que ele trabalha com amor e, portanto, entrega-se integralmente ao trabalho.

Ao ilustrar a relação de Akaki com seu trabalho, o narrador diz que "Tendo escrito até se fartar, ele deitava-se, sorrindo ao pensar no dia seguinte - no que Deus lhe mandaria para copiar". ${ }^{22}$ Aqui, Gogol descreve de forma clara a relação entre trabalho e religiosidade, mas não como acontece em sociedades calvinistas: a ética do trabalho é consonante ao tradicionalismo - assim como Honório, em "A carteira" -, conforme Weber retoma no seguinte trecho:

De início, em concordância com a tradição medieval predominante, conforme representada por Tomás de Aquino, por exemplo, o trabalho mundano, embora querido por Deus, a seu ver pertence ao reino das criaturas, é a base natural indispensável da vida de fé, moralmente indiferente em si mesmo como o comer e o beber. ${ }^{23}$

Assim, ao contrário da postura calvinista, para Akaki a religiosidade se associa ao trabalho - e não ao dinheiro, e muito menos ao lucro.

Outra demonstração da manutenção do tradicionalismo do protagonista é o fato de que, mesmo sendo ridicularizado pelos colegas de trabalho por causa de seu antigo capote, a principal motivação para sua troca é a necessidade de sobrevivência - uma vez que o antigo capote já não o protegia do frio, que já o machucava. Assim, a aparência, nesse momento, para Akaki, é importante apenas no nível relativo ao trabalho, e não à ostentação de seus bens - o que vai de encontro à última citação de Weber sobre o tradicionalismo (p. 72-73) e, também, ao seguinte trecho:

\footnotetext{
${ }^{20}$ GOGOL, p. 11

${ }^{21}$ GOGOL, p.13.

22 idem, p.9.

${ }^{23}$ WEBER, 2007, p. 72-73.
} 
Também um escritor moderno houve por bem formular o contraste que aparece no comportamento das duas confissões religiosas em face da vida econômica nos seguintes termos: “O católico (...) é mais sossegado; dotado de menor impulso aquisitivo, prefere um traçado de vida o mais possível seguro, mesmo que com rendimentos menores, a uma vida arriscada e agitada que eventualmente lhe trouxesse honras e riquezas. Diz por gracejo a voz do povo: 'bem comer ou bem dormir, há que escolher'. No presente caso, o protestante prefere comer bem, enquanto o católico quer dormir sossegado". ${ }^{24}$

O tradicionalismo de Akaki se revela, também, na passagem em que Akaki se recusa a subir de cargo, porque este, apesar de ser mais bem remunerado, exigiria mais trabalho.

Ao decidir comprar o novo capote, ele enfrenta um embate no que diz respeito à forma de conseguir dinheiro para isso, uma vez que ele era pobre e via o trabalho como única possibilidade de fonte de renda, em razão de sua moral - o que o torna, neste ponto, parecido com Honório, de "A carteira".

No momento em que Akaki decide economizar tudo o que fosse possível para comprar o novo capote, a importância da aparência toma outra dimensão: a beleza do novo capote e a forma como ele seria visto, agora, ganha espaço nos pensamentos do protagonista. Assim, sua vida passa a girar em torno do planejamento do capote, de modo a reforçar, agora de forma mais completa, a importância da aparência - além de moral, física. Dessa forma, ele passa a associar a expressão de seu crédito à aparência de um melhor crédito financeiro também. Essa mudança foge, então, à primeira motivação da compra de um novo capote e demonstra um pequeno desvio de sua moral inicial - o que fica evidente no seguinte excerto, referente ao momento de inauguração do novo capote:

Enquanto isso, Akaki Akakiévitch caminhava tomado pelo mais intenso júbilo. A sensação continuada do casaco novo sob seus ombros o mergulhava num devaneio que, por diversas vezes, arrancou dele pequenos sorrisos. ${ }^{25}$

Fica nítido, nesse momento, como Akaki associa a aparência ao status social. A beleza de seu novo capote é essencial para a mudança comportamental de Akaki - o que vai de encontro ao pensamento de Benjamin Franklin, o qual faz uma associação direta do crédito de um sujeito à sua aparência, no que diz respeito às ações. Assim, quando Akaki age conforme sua pretensa ascensão social, ele ganha notoriedade.

Contudo, embora sinta-se feliz com a conquista, Akaki se revela encabulado quando os colegas de trabalho o parabenizam demasiadamente - voltando, pois, a sua conduta de vida ligada à sobrevivência, com aversão à ostentação. Assim, ao preferir ser visto com uma vida modesta, Akaki volta à ética tradicionalista.

\footnotetext{
${ }^{24}$ WEBER, 2007, p. 34.

${ }^{25}$ GOGOL, p.33.
} 
Embora volte à modéstia, Akaki foi à festa oferecida pelo patrão e se sentiu importante em razão de caminhar sobre as ruas de um bairro nobre. Nesse momento, fica claro como a mudança de ambiente imprime diferentes percepções do sujeito sobre ele mesmo, de modo similar ao conto "O empréstimo", de Machado de Assis, em que o protagonista se sente importante por estar num ambiente de pessoas com prestígio social.

Após o roubo do capote e sua consequente frustração, Akaki morre em razão da perda de seu capote - símbolo de sua ascensão social ilusória. Segundo Anna Palma (2007, p. 186), “a perda da vestimenta que o funcionário público mandou costurar com muito sacrifício corresponde a anulação do Eu do mesmo" - e essa anulação determina sua morte. Assim como o fato de o fantasma de Akaki descansar apenas após a recuperação de um capote que indicasse status social elevado, a simbologia do capote revela, então, a dimensão que a aparência tomou para o personagem: já não bastava reiterar a associação de sua imagem à ética do trabalho, mas se tornou imprescindível expressar sua conduta em sua imagem física - condensada no capote, o que ilustra a associação da aparência moral de trabalhador à aparência física de credibilidade financeira.

Com essa análise, é possível concluir, portanto, que o tradicionalismo está presente na conduta de Akaki e que, em certo momento, ele se distancia dessa ética - o que não revela um rompimento com o tradicionalismo econômico e nem religioso, uma vez que o lucro não é cotado como objetivo. Assim, há apenas uma mudança de expressão do tradicionalismo.

\subsection{Retomada da semelhança da ética do trabalho presente nas obras}

As obras estudadas demonstram algumas similaridades em sua apresentação, a começar pela semelhança entre o significado dos nomes de ambos os protagonistas - os quais remetem à honra. Em segundo lugar - o que é mais importante -, após uma leitura minuciosa dos contos e após a leitura de As ideias fora do lugar, o contexto socioeconômico dos países se revela próximo, o que implica em condutas análogas no que diz respeito ao modo de lidar com os aspectos financeiros da vida. A modéstia é, então, presente nessas sociedades (e até mesmo os nomes dos protagonistas revelam a modéstia), mesmo que se apresente de forma simultânea ao desejo de aparentar um bom status social e, portanto, uma situação financeira favorável.

Estes contos são reflexo da sociedade que eles descrevem e demonstram, portanto, a ausência do desenvolvimento do capitalismo moderno nesses contextos. Segundo Schwarz, "Por sua mera presença, a escravidão indicava a impropriedade das idéias liberais; o que entretanto é menos que orientar-lhes o movimento. Sendo embora a relação produtiva fundamental, a escravidão não era o nexo efetivo da vida ideológica” (1992, p. 4). Assim, tais sociedades revelam a manutenção do tradicionalismo, embora indiquem alguns traços de mudança, se as compararmos de forma estrita às descrições de Weber de sociedades não calvinistas. 


\section{Considerações Finais}

Considerando a verossimilhança das obras, constata-se que as personagens e suas condutas representam a cultura da época das sociedades em que estão inseridas. Assim, esta análise evidenciou a ausência do espírito do capitalismo moderno em ambos os contextos - os quais, mesmo em uma observação superficial, são similares. Observamos, com isso, que em nenhuma das sociedades indicadas houve a ruptura com o tradicionalismo religioso nem com o tradicionalismo econômico - resultado daquele, como postulado por Weber. Essa manutenção dos tradicionalismos trouxe a ausência da cultura de investimentos - possível forma de superação de desigualdade, surgida em conjunto com outras modificações sociopolíticas. Dessa forma, é possível dizer que a ausência de fomento ao investimento corrobora a desigualdade social brasileira.

No Brasil, especificamente, o resultado da manutenção do tradicionalismo se revelou, entre outros momentos, durante o Encilhamento, em que muitas pessoas viam no jogo de ações um meio de superar a rigidez das camadas sociais, porém esse episódio foi palco de inúmeras especulações financeiras. Assim, parte da sociedade percebia o jogo como falta de moralidade, como alguns autores como Júlia Lopes de Almeida e Artur Azevedo retratam em suas obras, como A falência e O tribofe - contemporâneas à de Machado de Assis, o qual, em suas obras, também desenvolve personagens que fazem tal juízo de valor sobre o Encilhamento, como em Esaú e Jacó. Essa percepção social sobre o jogo de ações ilustra, portanto, a desconfiança no lucro e a ausência da cultura de investimentos típica de sociedades calvinistas.

Ademais, as implicações da manutenção do tradicionalismo são perceptíveis, inclusive, na atualidade, uma vez que ambos os países - mesmo com diferentes desenvolvimentos ao longo da história - tem como principal fonte de economia a exploração de recursos naturais, diferentemente de países que desenvolveram sua economia com foco no lucro e portanto, em produtos tecnológicos. Porém, estudos futuros podem avaliar essas percepções de forma mais aprofundada. Além disso, é importante ressaltar que aqui despontaram reflexões e análises relativas exclusivamente à economia aplicada à literatura, de forma a descrever as sociedades representadas nos contos sob a ótica weberiana à luz de Roberto Schwarz. Esta análise relata, portanto, duas sociedades antagônicas às calvinistas - descritas por Weber e associadas ao desenvolvimento do capitalismo moderno.

\section{RIFLESSIONI COMPARATIVE SULL'ETICA UTILITARISTICA NELLE OPERE "IL PORTAFOGLIO", DI MACHADO DE ASSIS, E "IL MANTELLO", DI NIKOLAI GOGOL}

Sintesi: Alla luce delle opere L'etica protestante e lo "spirito" del capitalismo, di Max Weber (2007), e As Ideias fora do Lugar, di Roberto Schwarz (1992), questa ricerca mira all'analisi comparativa dei 
racconti brevi "Il Portafoglio", di Machado de Assis (2019), e “O Capote”, di Nikolai Gogol (2001). Così, la contrapposizione dei contesti delle opere evidenziata grande somiglianza tra le società come Schwarz fa capire -, che riflette nella prossimità delle caratteristiche morali dei personaggi dei racconti. Queste caratteristiche, soprattutto per quanto riguarda l'economia, chiarire la discrepanza di etica presenti nei paesi protestanti - descritto da Weber. In "Il portafoglio", Machado presenta Honório come protagonista, che apprezza l'immagine di un uomo d'onore, e, soprattutto, il mantenimento dei suoi crediti sociali e finanziari, anche se sviluppa questioni morali in tutta la storia. In "Il mantello", Gogol fa di Akaki la rappresentazione dell'uomo che ama lavorare per il pregiudizio tradizionalista - senza mirare all'accumulo di denaro o di profitto. I racconti analizzati, perché sono veri, mostrano, rispettivamente, le caratteristiche sociali dell'Impero del Brasile e della Russia czarista e, quindi, i loro personaggi riproducono standard etici in vigore al momento - che ci permette di analizzare e confrontare le opere e i contesti in cui sono inserite. Attraverso questo lavoro, l'etica utilitaristica - predicata da Benjamin Franklin e descritta da Weber - si è dimostrata presente in entrambe le società, anche se il tradizionalismo era presente, il che ha evidenziato il fatto che tali elementi non sono esclusivisti.

Parole chiave: Economia; Etica utilitaristica; Letteratura comparata; Machado de Assis; Nikolai Gogol.

\section{Referências}

ASSIS, Joaquim Maria Machado de. A carteira. In: O espelho e outros contos. Jandira, SP: Principis, 2019. p. 7 - 10.

GOGOL, Nikolai Vassilievitch. O capote. Tradução: Roberto Gomes. Porto Alegre, RS: L\&PM, 2001.

Significado do nome Amélia. Significado de Nomes Próprios. Disponível em: <https://www.dicionariodenomesproprios.com.br/amelia/>. Acesso em: 26 de jul. de 2020.

Significado do nome - Akaki. Dream Book. Disponível em: $<$ https:// pt.dreambook.in.ua/name/man/akakiy/>. Acesso em: 26 de jul. de 2020.

Significado do nome Gustavo. Significado de Nomes Próprios. Disponível em: $<$ https://www.dicionariodenomesproprios.com.br/gustavo/>.

Acesso em: 26 de jul. de 2020.

Significado do nome Honório. Significado de Nomes Próprios. Disponível em: $<$ https://www.dicionariodenomesproprios.com.br/honorio/>. Acesso em: 26 de jul. de 2020.

SCHWARZ, Roberto. Ao vencedor as batatas. In: As idéias fora do lugar. São Paulo: Duas cidades, 1992.

SILVA, Ana Cláudia Suriani da. Gogol, matriz de Quincas Borba. In: Revista Santa Barbara Portuguese Studies, volume VII, p. 153- 170. Disponível em: <file:///C:/Users/Acer/Downloads/Gogol,\%20matriz\%20de\%200uincas\%20 Borba.pdf $>$. Acesso em: 20 de set. de 2020. 
PALMA, Anna. O duplo nos contos de Machado de Assis: Capítulo dos chapéus. In: Revista outra travessia, n.6. Disponível em: <https://periodicos.ufsc.br/index. php/Outra/article/view/2176-8552.2010n6p181>. Acesso em 15 de set. de 2020.

VIAL, Ana Paula Seixas; TOMAZZI, Raiany. Análise comparativa entre O capote, de Nikolai Gogol e O espelho, de Machado de Assis - o duplo na trajetória das personagens. In: Revista entrelinhas, v.6, n.1. Disponível em: <http://revistas. unisinos.br/index.php/entrelinhas/article/view/2612>.

Acesso em: 02 de set. de 2020.

WEBER, Max. A ética protestante e o "espírito" do capitalismo.

São Paulo: Schwarcz S.A., 2007.

Recebido em 06 de abril de 2021.

Aprovado em 10 de junho de 2021 